Article

\title{
Anti-Oxidant and Tyrosinase Inhibitory In Vitro Activity of Amino Acids and Small Peptides: New Hints for the Multifaceted Treatment of Neurologic and Metabolic Disfunctions
}

\author{
Grazia Luisi ${ }^{1}$, Azzurra Stefanucci ${ }^{1}$, Gokhan Zengin ${ }^{2}$, Marilisa Pia Dimmito ${ }^{1}$ and \\ Adriano Mollica ${ }^{1, *}$ (D) \\ 1 Department of Pharmacy, G. d'Annunzio University of Chieti-Pescara, 66100 Chieti, Italy; \\ gluisi@unich.it (G.L.); a.stefanucci@unich.it (A.S.); marilisa.dimmito@unich.it (M.P.D.) \\ 2 Department of Biology, Science Faculty, Selcuk University, Konya 42130, Turkey; \\ Gokhagokhanzengin@selcuk.edu.tr \\ * Correspondence: a.mollica@unich.it
}

Received: 15 November 2018; Accepted: 22 December 2018; Published: 26 December 2018

\begin{abstract}
Oxidative damage is among the factors associated with the onset of chronic pathologies, such as neurodegenerative and metabolic diseases. Several classes of anti-oxidant compounds have been suggested as having a protective role against cellular stressors, but, in this perspective, peptides' world represents a poorly explored source. In the present study, the free radical scavenging properties, the metal ion reducing power, and the metal chelating activity of a series of sulfurated amino acids and tripeptides were determined in vitro through canonical assays (DPPH, ABTS, CUPRAC, FRAP, PM, and EECC) and estimated in comparison with the corresponding activities of synthetic peptide semicarbazones, incorporating the peculiar non-proteinogenic amino acid, tert-leucine $(t$ Leu). The compounds exhibited remarkable anti-oxidant properties. As expected, sulfurated compounds 1-5 were found to be the most efficient radical scavengers and strongest reductants. Nevertheless, $t$ Leu-containing peptides $\mathbf{7}$ and $\mathbf{8}$ disclosed notable metal reducing and chelating activities. These unprecedented results indicate that $t$ Leu-featuring di- and tripeptide backbones, bearing the semicarbazone chelating moiety, are compatible with the emergence of an anti-oxidant potential. Additionally, when tested against a panel of enzymes usually targeted for therapeutic purposes in neurodegenerative and metabolic disorders, all samples were found to be good inhibitors of tyrosinase.
\end{abstract}

Keywords: anti-oxidant; scavenger; neurodegenerative diseases; metabolic disorders

\section{Introduction}

Since the first introduction of the term, "oxidative stress" (OS), by Helmut Sies a few decades ago [1], an overwhelming body of biomedical literature has flourished on the topic [2-5]. The original concept of the phenomenon refers to an undesired production of pro-oxidant species, such as oxygen (ROS) and nitrogen (RNS) free radicals, that are not adequately counterbalanced neither by the anti-oxidant defense mechanisms of the organism, nor by the supply of natural anti-oxidants, finally resulting in severe damage of lipids, proteins, and DNA. The OS meaning has now been updated to acknowledge free radicals positive role as redox-signaling molecules in healthy tissues of aerobic organisms [6,7]. Nevertheless, a plethora of studies has been reported on the claimed anti-oxidant properties of chemicals, foods, or plant components to underline the possible benefits against OS-related pathologies. It is otherwise well established that that the anti-oxidant mechanisms 
are based on the physiologic enzymatic and non-enzymatic redox buffering systems more than on nutritional supplements [8].

The overall anti-oxidant potential of a specific compound, whose chemical reactivity towards disparate toxic species may consistently differ, depends upon the variable contribution of features as the free radical scavenging capacity, the reducing and redox buffering effectiveness, and the metal-chelating properties. Accordingly, a range of specific anti-oxidant evaluation tests are available, which may be appropriately selected to gain information about the precise mechanism underlying a certain effect, and serve to characterize the anti-oxidant character in the whole, expressed as the total anti-oxidant capacity (TAC) of the compound. Since the TAC measures only part of the anti-oxidant power, usually excluding enzymatic activities, the non-enzymatic antioxidant capacity (NEAC) has been recently suggested as a more fitting term [9].

The radical scavenging property refers to the molecule ability to quench oxygen $(\mathrm{HO}, \mathrm{HOO}, \mathrm{ROO}$, $\mathrm{H}_{2} \mathrm{O}_{2}, \mathrm{O}_{2}{ }^{1}$ ), nitrogen (NO, $\mathrm{HOONO}$ ), and chlorine ( $\mathrm{HOCl}$ ) free radicals or radical generating species, thereby blocking radical chain reactions. Compounds of this type, also known as chain-breaking anti-oxidants, well apart from preventive anti-oxidants that inhibit the formation of reactive oxygen species, may act by two distinct mechanisms, which imply competition with biological substrates for the (i) hydrogen atom transfer (HAT), or the (ii) single electron transfer (SET) from radicals. In the majorities of assays for the HAT-based reactions, free radicals are thermally generated through the decomposition of azo-compounds. The oxygen radical absorbance capacity (ORAC) method, the total radical trapping antioxidant parameter (TRAP) test, and the lipid peroxidation assay (LPA) are commonly used. The assays for SET reactions compare the in vitro capacity of the anti-oxidant to reduce the oxidant cromophore in comparison with reference reactants as: Trolox, in the trolox equivalent antioxidant capacity (TEAC) test, 2,2'-azino-bis(3-ethylbenzothiazoline)-6-sulphonic acid (ABTS), in the ABTS radical scavenging efficacy assay, and 2,2-diphenyl-1-picrylhydrazyl (DPPH), in the DPPH analogous test. It should be borne in mind, however, that a precise boundary between these two mechanisms does not exist, so that ABTS and DPPH are commonly considered mixed-mode assays [10] (Table 1).

Reductant agents are electron-rich molecules, which exert their anti-oxidant effect by an electron-transfer mechanism. This character is determined through a panel of tests for the direct estimation of the reducing capacity of the substance, such as the ferric ion reducing antioxidant Power (FRAP), the cupric antioxidant capacity (CUPRAC) method, and the phosphomolybdenum (PM) assay. FRAP and CUPRAC tests measure the lowered concentration of ferric and cupric ions in solution, respectively. The PM assay is based on the reduction of a Mo (VI)-complex to the corresponding Mo (V)-adduct, without generation of free metal ions in solution.

Finally, the metal-chelating efficacy is of further significance to define the anti-oxidant character of a compound. This ability prevents the participation of transition metal ions, particularly iron and copper, in the generation of free radicals through Fenton's or Haber-Weiss' reactions. The transition metal ion chelating capacity of anti-oxidants is evaluated by means of two assays, one measuring the EDTA equivalent iron chelation capacity (EECC) and the other the carnosine equivalent iron chelation capacity (CECC). 
Table 1. In vitro anti-oxidant capacity assays used for assessing the total anti-oxidant capacity (TAC) of compounds 1-9.

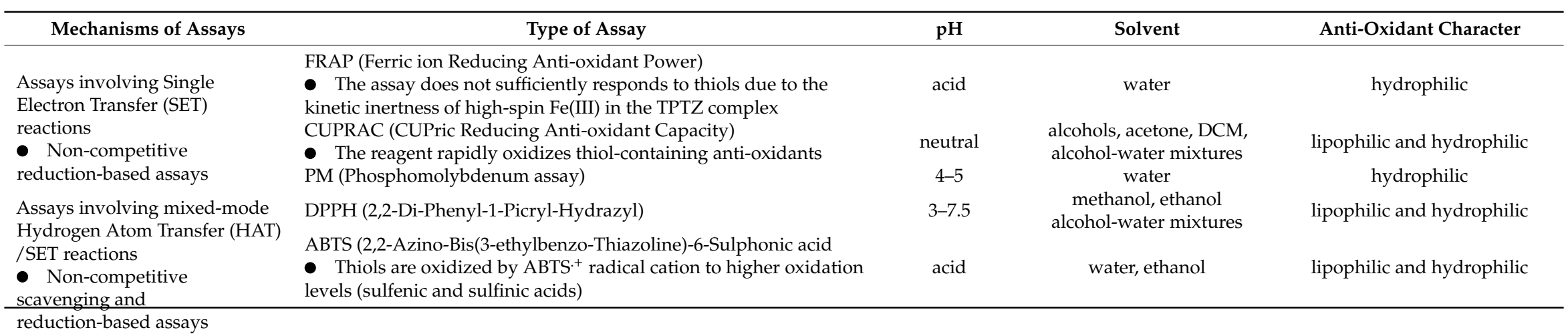


It should be considered that experimental results obtained with different methods may sensibly deviate, and the anti-oxidant activity rank have a dissimilar trend, due to many factors including, apart from different chemotypes and mechanisms, light, oxygen, $\mathrm{pH}$, and solvent nature.

Even though, in a number of cases, biological results may be debatable, ongoing investigation on natural agents is encouraged by the well-established link between the oxidative burden and a variety of strongly interconnected human pathologies, including neurodegenerative disorders, metabolic syndrome, cardiovascular diseases, type 2 diabetes (T2D), inflammation, and cancer [11,12]. Several lines of evidence support the role played by oxidative stress in etiology and progression of Alzheimer's disease (AD) and Parkinson's disease (PD), characterized by progressive synapse decline and neuronal loss in specific brain areas [13]. Lipid peroxidation, DNA and RNA damage, protein carbonylation, cross-linking, and fragmentation are common oxidative stress-induced hallmarks of AD and PD. Mitochondrial damage consequent to $\alpha$-amyloid (AD) or $\alpha$-synuclein (PD) overproduction results in ROS generation, which triggers neuronal injury and apoptosis through disruption of membrane phospholipids and the release of highly reactive malondialdehyde and 4-hydroxy-2,3-nonenal as oxidation by-products and markers, oxidative inactivation of nucleic acid and ATP-related enzymes, and redox imbalance-related increase of oxidized/misfolded proteins [14]. In analogy, oxidative stress is a major risk factor for the development of metabolic diseases. Results from in vitro and in vivo studies suggest that ROS-induced pre-adipocyte proliferation and increase in size of differentiated adipocytes have a causal role in obesity. It has also been disclosed that the selective increase in ROS production in accumulated fat leads to elevation of systemic oxidative stress and is, at least in part, the cause of dysregulation of adipocytokines [15].

One of the most attractive sources of bioactive compounds is represented by peptides: In view of their chemical and structural versatility, along with the intrinsic absence of detrimental effects, they represent ideal molecules to be unveiled as anti-oxidant candidates.

As a prosecution of our ongoing research on bioactive peptides [16-19], we were interested at first in a comparative in vitro investigation on the anti-oxidant properties of sulfurated amino acids considered either as single units or incorporated in small peptides. Sulfur-containing compounds under study included L-cysteine (Cys) (1) with the related thiol-tripeptides, glutathione [H-Glu(Cys-Gly-OH)-OH, GSH] (2), and its synthetic gamma-oxa-analogue H-Glo(Cys-Gly-OH)-OH (3), and the amino acids, L-cystine (4), L-ergothioneine (EGT) (5), and taurine (Tau) (6) (Figure 1).
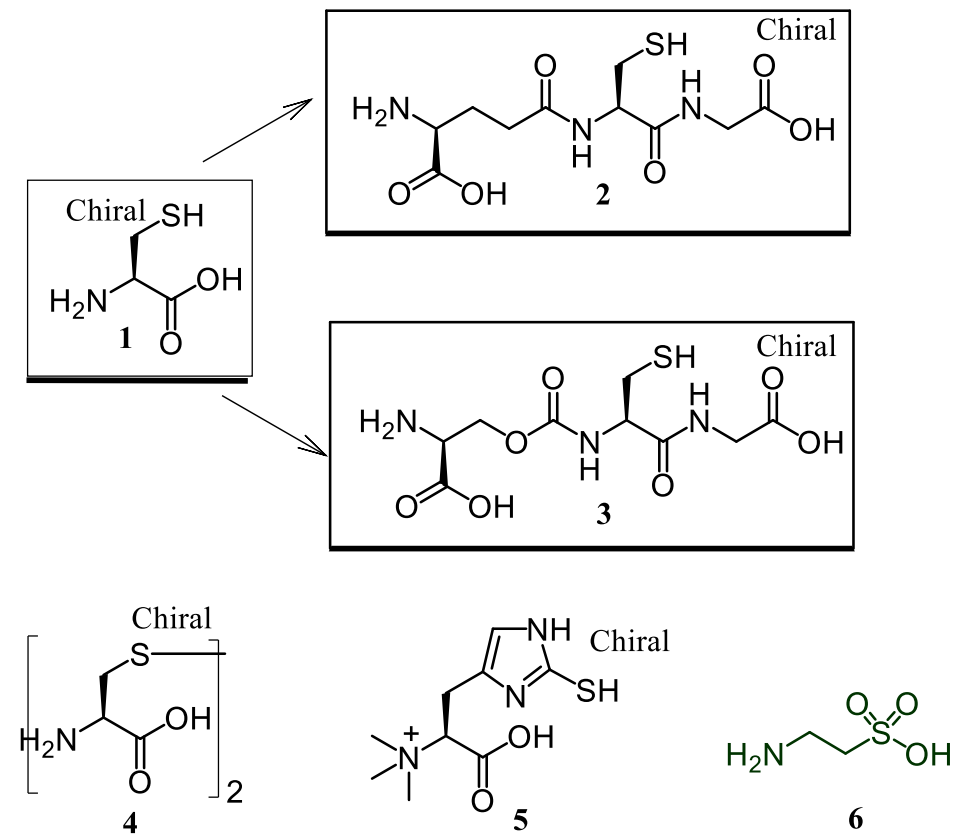

Figure 1. Chemical structures of sulfurated compounds 1-6. 
Additionally, a further set of synthetic compounds, namely Z-tLeu-Asp(OtBu)-Sc (7), Ac-tLeu-Leu-Asp $(\mathrm{O} t \mathrm{Bu})-\mathrm{Sc}(8)$, and ethyl 2-(D,L)-tert-butyl-mono-malonate (9), were considered in the same study to assess their unprecedented anti-oxidant properties (Figure 2).

The anti-oxidant profile of compounds 1-9 was estimated by means of six complementary in vitro assays (DPPH, ABTS, CUPRAC, FRAP, PM, and EECC). Results are collectively reported in Table 2.<smiles>CC(C)(C)OC(=O)C[C@@H](/C=N/NC(N)=O)NC(=O)[C@H](NC(=O)OCc1ccccc1)C(C)(C)C</smiles>

7<smiles></smiles>

8<smiles>CCOC(=O)[C@H](C(=O)O)C(C)(C)C</smiles>

9

Figure 2. Chemical structures of $t$ Leu-based semicarbazones $\mathbf{7}$ and $\mathbf{8}$ and tert-butyl ethyl malonate $\mathbf{9}$.

There is accumulating evidence that, in addition to the oxidative damage, the (abnormal) catalytic activity of certain enzymes contribute to the development and progression of neurodegenerative and metabolic disorders; thus, in order to better characterize the protective profile of 1-9, with the hope of disclosing novel multifunctional compounds that can simultaneously modulate various interconnected pathological pathways, we tested their inhibitory effects on the following standard battery of enzymes: Acetylcholinesterase (AChE), butyrylcholinesterase (BChE), tyrosinase, $\alpha$-glucosidase, and $\alpha$-amylase. Enzyme inhibition is one of the most fruitful strategies in drug research. The inhibition of key enzymes could alleviate observed symptoms in a variety of pathologies, including Alzheimer's disease (AD), type 2 diabetes (T2D), obesity, and skin hyperpigmentation [20]. According to the cholinergic hypothesis [21], the approach of inhibiting cholinesterases is widely pursued for the restoration of impaired cholinergic function in AD [22] to improve memory function. Targeting tyrosinase is another frequent strategy thought to be beneficial in the prevention of neuronal degeneration as well as hyperpigmentation problems [23], since the monophenolase activity of this enzyme catalyzes the intermediate conversion of tyrosine in L-DOPA, which is an essential and rate-limiting step in melanin synthesis [24]. Again, considering that $\alpha$-glucosidase and $\alpha$-amylase are main enzymes in the carbohydrate catabolism, their inhibition could control blood glucose levels in T2D patients $[25,26]$. Taken together, the discovery of novel enzyme inhibitors is of great interest to combat the aforementioned diseases in the scientific platform.

The inhibitory activities of our compounds, 1-9, on selected enzymes are compared in Table 3. 
Table 2. Antioxidant capacity evaluation for compounds 1-9.

\begin{tabular}{|c|c|c|c|c|c|c|}
\hline Compounds & $\begin{array}{c}\text { DPPH } \\
\text { (mgTE/g Sample) }\end{array}$ & $\begin{array}{c}\text { ABTS } \\
\text { (mgTE/g Sample) }\end{array}$ & $\begin{array}{c}\text { CUPRAC } \\
\text { (mgTE/g Sample) }\end{array}$ & $\begin{array}{c}\text { FRAP } \\
\text { (mgTE/g Sample) }\end{array}$ & $\begin{array}{l}\text { Phosphomolybdenum } \\
\text { (mmolTE/g Sample) }\end{array}$ & $\begin{array}{c}\text { Metal Chelating } \\
\text { (mgEDTAE/g Sample) }\end{array}$ \\
\hline L-cysteine (1) & $102.50 \pm 1.43^{\mathrm{a}}$ & $245.14 \pm 0.21^{\mathrm{a}}$ & $939.97 \pm 2.96^{\mathrm{a}}$ & $761.90 \pm 16.69^{a}$ & $2.28 \pm 0.02^{b}$ & not active \\
\hline GSH (2) & $65.48 \pm 2.81^{b}$ & $196.89 \pm 0.38^{b}$ & $389.74 \pm 7.88^{c}$ & $143.03 \pm 6.68^{c}$ & $2.50 \pm 0.11^{\mathrm{a}}$ & not active \\
\hline H-Glo(Cys-Gly-OH)-OH (3) & $106.07 \pm 0.54^{\mathrm{a}}$ & not active & $69.36 \pm 0.97^{\mathrm{f}}$ & $41.44 \pm 0.86^{\mathrm{c}}$ & $0.21 \pm 0.04^{\mathrm{e}}$ & $70.91 \pm 0.17^{b}$ \\
\hline L-cystine (4) & $100.79 \pm 0.40^{a}$ & $1.20 \pm 0.08^{\mathrm{f}}$ & $124.72 \pm 4.13^{\mathrm{d}}$ & $41.59 \pm 0.35^{\mathrm{e}}$ & $0.11 \pm 0.01^{\mathrm{f}}$ & $84.77 \pm 0.11^{\mathrm{a}}$ \\
\hline Ergothioneine (5) & $73.23 \pm 0.13^{c}$ & $123.88 \pm 0.24^{\mathrm{c}}$ & $534.55 \pm 7.87^{b}$ & $114.94 \pm 1.75^{\mathrm{d}}$ & $2.46 \pm 0.02^{\mathrm{a}}$ & $1.35 \pm 0.27^{\mathrm{f}}$ \\
\hline Taurine (6) & not active & $5.47 \pm 0.14 \mathrm{e}^{\mathrm{e}}$ & $26.19 \pm 0.53 \mathrm{~g}$ & $13.47 \pm 0.63^{a}$ & $0.05 \pm 0.01 \mathrm{~g}$ & $20.45 \pm 2.08^{\mathrm{d}}$ \\
\hline Z-tleu-Asp (OtBu)-Sc (7) & not active & not active & $84.30 \pm 1.39$ e & $30.33 \pm 1.44^{\mathrm{f}}$ & $0.36 \pm 0.01 \mathrm{~d}$ & $43.69 \pm 3.40^{c}$ \\
\hline Ac- $t$ Leu-Leu-Asp(OtBu)-Sc (8) & not active & $48.01 \pm 1.41^{\mathrm{d}}$ & $81.31 \pm 1.85^{\mathrm{e}}$ & $170.47 \pm 5.50^{b}$ & $2.62 \pm 0.13^{\mathrm{a}}$ & $82.70 \pm 3.01^{\mathrm{a}}$ \\
\hline
\end{tabular}

TE, Trolox equivalents; EDTAE, Ethylenediaminetetraacetic acid equivalents; different letters indicate differences in the tested samples $(p<0.05)$.

Table 3. In vitro enzymatic assays for compounds 1-9.

\begin{tabular}{|c|c|c|c|c|c|}
\hline Compounds & $\begin{array}{l}\text { AChE Inhibition } \\
\text { (mgGALAE/g) }\end{array}$ & $\begin{array}{l}\text { BChE Inhibition } \\
\text { (mgGALAE/g) }\end{array}$ & $\begin{array}{c}\text { Tyrosinase Inhibition } \\
\text { (mgKAE/g) }\end{array}$ & $\begin{array}{c}\text { Amylase Inhibition } \\
\text { (mmolACAE/g) }\end{array}$ & $\begin{array}{l}\text { Glucosidase Inhibition } \\
\text { (mmolACAE/g Sample) }\end{array}$ \\
\hline L-cysteine (1) & $5.12 \pm 0.15^{\mathrm{a}}$ & $6.14 \pm 0.08^{a b}$ & $216.40 \pm 0.17^{\mathrm{a}}$ & $0.06 \pm 0.01{ }^{\mathrm{e}}$ & not active \\
\hline GSH (2) & $3.62 \pm 0.04^{b}$ & $6.13 \pm 0.12^{\mathrm{ab}}$ & $45.60 \pm 0.15^{\mathrm{e}}$ & $0.03 \pm 0.01^{\mathrm{f}}$ & not active \\
\hline H-Glo(Cys-Gly-OH)-OH (3) & not active & $6.39 \pm 0.01^{\mathrm{a}}$ & $216.95 \pm 0.17^{\mathrm{a}}$ & $1.37 \pm 0.03^{b}$ & $1.69 \pm 0.01^{b}$ \\
\hline L-cystine (4) & $5.24 \pm 0.02^{a}$ & $6.38 \pm 0.01^{\mathrm{a}}$ & $217.16 \pm 0.55^{\mathrm{a}}$ & $1.95 \pm 0.04^{\mathrm{a}}$ & $1.68 \pm 0.02^{b}$ \\
\hline Ergothioneine (5) & $3.01 \pm 0.01^{\mathrm{c}}$ & $0.18 \pm 0.05^{\mathrm{d}}$ & $100.97 \pm 1.71^{\mathrm{d}}$ & $0.07 \pm 0.01^{\mathrm{e}}$ & not active \\
\hline Taurine (6) & $0.45 \pm 0.03^{\mathrm{e}}$ & $0.07 \pm 0.01^{\mathrm{e}}$ & $33.87 \pm 1.59^{f}$ & $0.07 \pm 0.01^{\mathrm{e}}$ & $3.96 \pm 0.95^{\mathrm{a}}$ \\
\hline Z-tleu-Asp (OtBu)-Sc (7) & not active & $6.37 \pm 0.01^{\mathrm{a}}$ & $163.87 \pm 0.90^{b}$ & $0.31 \pm 0.06^{c}$ & $1.69 \pm 0.01^{b}$ \\
\hline Ac- $t$ Leu-Leu-Asp $(\mathrm{O} t \mathrm{Bu})-\mathrm{Sc}(\mathbf{8})$ & $5.17 \pm 0.07^{\mathrm{a}}$ & $6.33 \pm 0.01^{\mathrm{a}}$ & $152.69 \pm 1.19^{c}$ & $0.39 \pm 0.08^{c}$ & not active \\
\hline ethyl 2-tBu-(DL)-mono-malonate (9) & $2.61 \pm 0.01^{d}$ & $2.96 \pm 0.08^{c}$ & $45.37 \pm 0.52^{\mathrm{e}}$ & $0.20 \pm 0.02^{\mathrm{d}}$ & $0.84 \pm 0.01^{\mathrm{c}}$ \\
\hline
\end{tabular}

GALAE, Galatamine equivalents; KAE, Kojic acid equivalents; ACAE, Acarbose equivalents; different letters indicate differences in the tested samples $(p<0.05)$. 


\section{Materials and Methods}

\subsection{Chemistry}

Diethyl 2-tert-butyl-malonate, glutathione (GSH), amino acids, and their derivatives were purchased from Sigma-Aldrich. All other reagents and solvent were of analytical grade and were supplied from Sigma-Aldrich (Milano, Italy). The synthetic protocol for compound 3 has been previously described [27], as well as the preparative routes to peptides 7 [28] and 8 [17]. ${ }^{1} \mathrm{H}-$ and ${ }^{13} \mathrm{C}-\mathrm{NMR}$ experiments (compound 9) were recorded on a Varian VXR $300 \mathrm{MHz}$ instrument ( $\delta$ expressed in ppm). Ethyl 2-(D,L)-tert-butyl-mono-malonate (9).

Diethyl 2-tert-butyl-malonate $(0.71 \mathrm{~g}, 3.3 \mathrm{mmol})$ and catalytic amounts of $\mathrm{H}_{2} \mathrm{O}(1 \mathrm{~mL})$ were added under stirring to a solution of $\mathrm{KOH}(0.18 \mathrm{~g}, 0.3 \mathrm{mmol})$ in absolute $\mathrm{EtOH}(7 \mathrm{~mL})$. After $17 \mathrm{~h}$ at room temperature, the solvent was evaporated under reduced pressure, the residue taken up in $5 \% \mathrm{NaHCO}_{3}$, and the resulting aqueous solution washed with AcOEt before acidification by means of $6 \mathrm{~N} \mathrm{HCl}$. The aqueous phase $(\mathrm{pH}=1)$ was then extracted with AcOEt and the organic layers washed with $\mathrm{H}_{2} \mathrm{O}$. Drying and evaporation of the solvent in vacuo gave the expected mono-ester 9 as an oil (82\%), pure on TLC. $R_{\mathrm{f}}\left(\mathrm{CHCl}_{3} / \mathrm{MeOH} 99: 1\right)=0.65 ;{ }^{1} \mathrm{H}-\mathrm{NMR}\left(\mathrm{CDCl}_{3}\right): \delta 1.12\left(\mathrm{~s}, 9 \mathrm{H}, t \mathrm{Bu} \mathrm{CH}_{3}\right), 1.28(\mathrm{~d} \mathrm{t}$, $\left.{ }^{3} \mathrm{~J}=7.3 \mathrm{~Hz},{ }^{6} \mathrm{~J}=0.6 \mathrm{~Hz}, 3 \mathrm{H}, \mathrm{OCH}_{2} \mathrm{CH}_{3}\right), 3.25\left(\mathrm{~d},{ }^{6} \mathrm{~J}=0.6 \mathrm{~Hz}, 1 \mathrm{H},(\alpha)-\mathrm{CH}\right), 4.20\left(\mathrm{br} \mathrm{q},{ }^{3} \mathrm{~J}=7.3 \mathrm{~Hz}\right.$, $\left.2 \mathrm{H}, \mathrm{OCH}_{2} \mathrm{CH}_{3}\right), 10.0$ (br s, $\left.1 \mathrm{H}, \mathrm{COOH}\right) .{ }^{13} \mathrm{C}-\mathrm{NMR}\left(\mathrm{CDCl}_{3}\right): \delta 14.29\left(\mathrm{OCH}_{2} \mathrm{CH}_{3}\right), 28.28\left(t \mathrm{Bu} \mathrm{CH}_{3}\right)$, $34.43(\mathrm{C}(\alpha)), 61.28\left(\mathrm{OCH}_{2} \mathrm{CH}_{3}\right), 61.71(\mathrm{C}(\alpha)), 169.74(\mathrm{COOR}), 173.32(\mathrm{COOH})$.

\subsection{Biological Studies}

Antioxidant (DPPH and ABTS radical scavenging, reducing power (CUPRAC and FRAP), phosphomolybdenum and metal chelating (ferrozine method)) and enzyme inhibitory activities (cholinesterase (Elmann's method), tyrosinase (dopachrome method), $\alpha$-amylase (iodine/potassium iodide method) and $\alpha$-glucosidase (chromogenic PNPG method)) were determined using the methods previously described by our published paper [29]. Spectrophotometric measurements for antioxidant and enzyme inhibitory assays were performed with Thermo Scientific Multiskan GO (Thermo Fisher Scientific, Vantaa, Finland).

For the DPPH (1,1-diphenyl-2-picrylhydrazyl) radical scavenging assay: Sample solution $(1 \mathrm{mg} / \mathrm{mL} ; 1 \mathrm{~mL})$ was added to $4 \mathrm{~mL}$ of a $0.004 \%$ methanol solution of DPPH. The sample absorbance was read at $517 \mathrm{~nm}$ after a $30 \mathrm{~min}$ incubation at room temperature in the dark. DPPH radical scavenging activity was expressed as milligrams of trolox equivalents (mg TE/g sample).

For the ABTS (2,2'-azino-bis(3-ethylbenzothiazoline) 6-sulfonic acid) radical scavenging assay: Briefly, ABTS+ was produced directly by reacting $7 \mathrm{mM}$ ABTS solution with $2.45 \mathrm{mM}$ potassium persulfate and the mixture was allowed to stand for $12-16 \mathrm{~h}$ in the dark at room temperature. Prior to beginning the assay, ABTS solution was diluted with methanol to an absorbance of $0.700 \pm 0.02$ at $734 \mathrm{~nm}$. Sample solution $(1 \mathrm{mg} / \mathrm{mL} ; 1 \mathrm{~mL})$ was added to ABTS solution $(2 \mathrm{~mL})$ and mixed. The sample absorbance was read at $734 \mathrm{~nm}$ after a $30 \mathrm{~min}$ incubation at room temperature. The ABTS radical scavenging activity was expressed as milligrams of trolox equivalents ( $\mathrm{mg} \mathrm{TE} / \mathrm{g}$ sample).

For the CUPRAC (cupric ion reducing activity) activity assay: Sample solution $(1 \mathrm{mg} / \mathrm{mL} ; 0.5 \mathrm{~mL})$ was added to premixed reaction mixture containing $\mathrm{CuCl}_{2}(1 \mathrm{~mL}, 10 \mathrm{mM})$, neocuproine $(1 \mathrm{~mL}, 7.5 \mathrm{mM})$, and $\mathrm{NH}_{4} \mathrm{Ac}$ buffer $(1 \mathrm{~mL}, 1 \mathrm{M}, \mathrm{pH}$ 7.0). Similarly, a blank was prepared by adding sample solution $(0.5 \mathrm{~mL})$ to a premixed reaction mixture $(3 \mathrm{~mL})$ without $\mathrm{CuCl}_{2}$. Then, the sample and blank absorbances were read at $450 \mathrm{~nm}$ after a $30 \mathrm{~min}$ incubation at room temperature. The absorbance of the blank was subtracted from that of the sample. CUPRAC activity was expressed as milligrams of trolox equivalents (mg TE/g sample).

For the FRAP (ferric reducing antioxidant power) activity assay: Sample solution $(1 \mathrm{mg} / \mathrm{mL}$; $0.1 \mathrm{~mL})$ was added to premixed FRAP reagent $(2 \mathrm{~mL})$ containing acetate buffer $(0.3 \mathrm{M}, \mathrm{pH} 3.6)$, 2,4,6-tris (2-pyridyl)-S-triazine (TPTZ) $(10 \mathrm{mM})$ in $40 \mathrm{mM} \mathrm{HCl}$, and ferric chloride $(20 \mathrm{mM})$ in a ratio of 
10:1:1 $(v / v / v)$. Then, the sample absorbance was read at $593 \mathrm{~nm}$ after a $30 \mathrm{~min}$ incubation at room temperature. FRAP activity was expressed as milligrams of trolox equivalents (mg TE/g sample).

For the PM method: Sample solution $(1 \mathrm{mg} / \mathrm{mL} ; 0.3 \mathrm{~mL})$ was combined with $3 \mathrm{~mL}$ of reagent solution ( $0.6 \mathrm{M}$ sulfuric acid, $28 \mathrm{mM}$ sodium phosphate, and $4 \mathrm{mM}$ ammonium molybdate). The sample absorbance was read at $695 \mathrm{~nm}$ after a $90 \mathrm{~min}$ incubation at $95^{\circ} \mathrm{C}$. The total antioxidant capacity was expressed as millimoles of trolox equivalents (mmol TE/g sample).

For the metal chelating activity assay: Briefly, sample solution $(1 \mathrm{mg} / \mathrm{mL} ; 2 \mathrm{~mL})$ was added to $\mathrm{FeCl}_{2}$ solution $(0.05 \mathrm{~mL}, 2 \mathrm{mM})$. The reaction was initiated by the addition of $5 \mathrm{mM}$ ferrozine $(0.2 \mathrm{~mL})$. Similarly, a blank was prepared by adding sample solution $(2 \mathrm{~mL})$ to $\mathrm{FeCl}_{2}$ solution $(0.05 \mathrm{~mL}, 2 \mathrm{mM})$ and water $(0.2 \mathrm{~mL})$ without ferrozine. Then, the sample and blank absorbances were read at $562 \mathrm{~nm}$ after a 10 min incubation at room temperature. The absorbance of the blank was subtracted from that of the sample. The metal chelating activity was expressed as milligrams of EDTA (disodium edetate) equivalents (mg EDTAE/g sample).

For the cholinesterase (ChE) inhibitory activity assay: Sample solution $(1 \mathrm{mg} / \mathrm{mL} ; 50 \mu \mathrm{L})$ was mixed with DTNB (5,5-dithio-bis(2-nitrobenzoic) acid (Sigma, St. Louis, MO, USA) (125 $\mu \mathrm{L})$ and AChE (acetylcholinesterase (Electric ell acetylcholinesterase, Type-VI-S, EC 3.1.1.7, Sigma)), or BChE (butyrylcholinesterase (horse serum butyrylcholinesterase, EC 3.1.1.8, Sigma)) solution $(25 \mu \mathrm{L})$ in Tris- $\mathrm{HCl}$ buffer ( $\mathrm{pH}$ 8.0) in a 96-well microplate and incubated for $15 \mathrm{~min}$ at $25{ }^{\circ} \mathrm{C}$. The reaction was then initiated with the addition of acetylthiocholine iodide (ATCI, Sigma) or butyrylthiocholine chloride (BTCl, Sigma) (25 $\mu \mathrm{L})$. Similarly, a blank was prepared by adding sample solution to all reaction reagents without enzyme (AChE or $\mathrm{BChE})$ solution. The sample and blank absorbances were read at $405 \mathrm{~nm}$ after $10 \mathrm{~min}$ incubation at $25^{\circ} \mathrm{C}$. The absorbance of the blank was subtracted from that of the sample and the cholinesterase inhibitory activity was expressed as galantamine equivalents (mgGALAE/g sample).

For the tyrosinase inhibitory activity assay: Sample solution $(1 \mathrm{mg} / \mathrm{mL} ; 25 \mu \mathrm{L})$ was mixed with tyrosinase solution ( $40 \mu \mathrm{L}$, Sigma) and phosphate buffer $(100 \mu \mathrm{L}, \mathrm{pH} 6.8)$ in a 96 -well microplate and incubated for $15 \mathrm{~min}$ at $25^{\circ} \mathrm{C}$. The reaction was then initiated with the addition of L-DOPA $(40 \mu \mathrm{L}$, Sigma). Similarly, a blank was prepared by adding sample solution to all reaction reagents without enzyme (tyrosinase) solution. The sample and blank absorbances were read at $492 \mathrm{~nm}$ after a $10 \mathrm{~min}$ incubation at $25^{\circ} \mathrm{C}$. The absorbance of the blank was subtracted from that of the sample and the tyrosinase inhibitory activity was expressed as kojic acid equivalents (mgKAE/g sample).

For the $\alpha$-amylase inhibitory activity assay: Sample solution $(1 \mathrm{mg} / \mathrm{mL} ; 25 \mu \mathrm{L})$ was mixed with $\alpha$-amylase solution (ex-porcine pancreas, EC 3.2.1.1, Sigma) $(50 \mu \mathrm{L})$ in phosphate buffer (pH 6.9 with $6 \mathrm{mM}$ sodium chloride) in a 96-well microplate and incubated for $10 \mathrm{~min}$ at $37^{\circ} \mathrm{C}$. After pre-incubation, the reaction was initiated with the addition of starch solution (50 $\mu \mathrm{L}, 0.05 \%)$. Similarly, a blank was prepared by adding sample solution to all reaction reagents without enzyme ( $\alpha$-amylase) solution. The reaction mixture was incubated for $10 \mathrm{~min}$ at $37^{\circ} \mathrm{C}$. The reaction was then stopped with the addition of $\mathrm{HCl}(25 \mu \mathrm{L}, 1 \mathrm{M})$. This was followed by addition of the iodine-potassium iodide solution $(100 \mu \mathrm{L})$. The sample and blank absorbances were read at $630 \mathrm{~nm}$. The absorbance of the blank was subtracted from that of the sample and the $\alpha$-amylase inhibitory activity was expressed as acarbose equivalents (mmol ACE/g sample).

For the $\alpha$-glucosidase inhibitory activity assay: Sample solution $(1 \mathrm{mg} / \mathrm{mL} ; 50 \mu \mathrm{L})$ was mixed with glutathione $(50 \mu \mathrm{L}$ ) and $\alpha$-glucosidase solution (from Saccharomyces cerevisiae, EC 3.2.1.20, Sigma) $(50 \mu \mathrm{L})$ in phosphate buffer (pH 6.8) and PNPG (4-nitro-phenyl- $\alpha$-D-glucopyranoside, Sigma) $(50 \mu \mathrm{L})$ in a 96-well microplate and incubated for $15 \mathrm{~min}$ at $37^{\circ} \mathrm{C}$. Similarly, a blank was prepared by adding sample solution to all reaction reagents without enzyme ( $\alpha$-glucosidase) solution. The reaction was then stopped with the addition of sodium carbonate $(50 \mu \mathrm{L}, 0.2 \mathrm{M})$. The sample and blank absorbances were read at $400 \mathrm{~nm}$. The absorbance of the blank was subtracted from that of the sample and the $\alpha$-glucosidase inhibitory activity was expressed as acarbose equivalents (mmol ACE/g sample). One-way analysis of variance (ANOVA) was done to determine any differences between the tested 
samples following a Tukey's test. $p<0.05$ were assigned to be statistically significant. The statistical procedures were performed by SPPS v. 17.0.

\section{Results and Discussion}

Compounds 1-6 are representative of a different oxidation status of the sulfur atom, and their electron-donating character varies accordingly. Compounds 1-3 contain a sulfhydryl group, which is strongly nucleophilic and may act as a radical quencher, reductant, and metal chelator. GSH (2) is the most abundant intracellular thiol in mammals, and its role as a detoxifying agent is not questionable. In its anti-oxidant behavior, the natural tripeptide was compared to analogue 3, containing a stable OCONH bond as the CONH surrogate at the $(\alpha)$-glutamyl junction, which has been previously reported in the course of our previous studies on GSH chemical modification [27,30]. The protective effects of EGT (5) against the oxidative damage, both in vitro and in vivo, have been widely documented, despite some conflicting results [31]. This natural betaine derivative is characterized by a distinctive thione/thiol tautomeric function. L-cystine (4), presenting a disulfide bridge, is prone to oxidative demolition to form sulfenic, sulfinic, and sulfonic species. The last compound in the series, taurine (6), contains a completely oxidized sulfur atom. Table 2 summarizes the efficiency data for compounds 1-9 in terms of their free radical scavenging ability (ABTS and DPPH), reducing power (CUPRAC, FRAP, and PM), and metal chelating activity.

In the group of sulfurated compounds analyzed in this study, 1-5 present an excellent anti-oxidant profile. In detail, compounds 1-5 exhibited good DPPH scavenging activities, with well-aligned values ranging from $106.07 \pm 0.57 \mathrm{mg} \mathrm{TE} / \mathrm{g}$ sample, for the glutathione oxa-analogue 3, to $65.48 \pm 2.8157 \mathrm{mg}$ TE/g sample, for GSH (2), whilst taurine (6) was found devoid of activity. The radical scavenging activity was found to decrease in the order: H-Glo(Cys-Gly-OH)-OH (3) $\geq$ L-cysteine (1) $\geq$ L-cystine (4) > EGT (5) $\geq$ GSH (2).

In the ABTS assay, L-cysteine (1), GSH (2), and EGT (5) showed the highest radical cation scavenging ability $(245.14 \pm 0.21 \mathrm{mg} \mathrm{TE} / \mathrm{g}$ sample, $196.89 \pm 0.38 \mathrm{mg} \mathrm{TE} / \mathrm{g}$ sample, and $123.88 \pm 0.24 \mathrm{mg}$ TE/g sample, respectively), compared to compounds 3, 4, and 6, which do not trap $\mathrm{ABTS}^{\bullet+}$ effectively.

Quite notable results were obtained also in the CUPRAC reducing power assay conducted on 1-6, with the strongest activity shown by L-cysteine (1) (939.97 $\pm 2.96 \mathrm{mg}$ TE/g sample), followed by, in descending order, EGT (5) (534.55 $\pm 7.87 \mathrm{mg}$ TE/g sample), GSH (2) (389.74 $\pm 7.88 \mathrm{mg}$ TE/g sample), L-cystine (4) (124.72 $\pm 4.13 \mathrm{mg} \mathrm{TE} / \mathrm{g}$ sample), and the isosteric glutathione 3 (69.36 $\pm 0.97 \mathrm{mg} \mathrm{TE} / \mathrm{g}$ sample). Taurine (6) showed the lowest activity in the assay, presenting a value of $26.19 \pm 0.53 \mathrm{mg}$ TE/g sample.

A similar trend was observed for the sulfurated compounds in the FRAP rank, with their $\mathrm{Fe}^{3+}$ reducing activities descending in the following order $1>>2>5>4 \approx 3>6$. A significant value was registered for L-cysteine (1) (761.90 $\pm 16.69 \mathrm{mg}$ TE/g sample), resulting 5-, 6-, and even 18-fold higher than the corresponding parameters of GSH (2) (143.03 $\pm 6.68 \mathrm{mg}$ TE/g sample), EGT (5) (114.94 $\pm 1.75 \mathrm{mg} \mathrm{TE} / \mathrm{g}$ sample), and the lined-up couple, L-cystine (4) (41.59 $\pm 0.35 \mathrm{mg} \mathrm{TE} / \mathrm{g}$ sample) and H-Glo(Cys-Gly-OH)-OH (3) (41.44 $\pm 0.86 \mathrm{mg}$ TE/g sample), respectively.

In the PM assay, the most efficient compounds were, in descending order, GSH (2) (2.50 $\pm 0.11 \mathrm{mmol}$ TE/g sample), EGT (5) (2.46 $\pm 0.02 \mathrm{mmol} \mathrm{TE} / \mathrm{g}$ sample), and L-cysteine (1) (2.28 $\pm 0.02 \mathrm{mmol} \mathrm{TE} / \mathrm{g}$ sample), while the remaining 3, 4, and 6 exhibited only modest or negligible activity.

Finally, L-cystine (4) and H-Glo(Cys-Gly-OH)-OH (3) are the only sulfur-containing compounds to reveal a consistent and comparable metal chelating activity $(84.77 \pm 0.11 \mathrm{mg}$ EDTAE/g sample and $70.91 \pm 0.17 \mathrm{mg}$ EDTAE/g sample, respectively), followed by taurine (6) with a ca. 4-fold decrease in efficacy (20.45 $\pm 2.08 \mathrm{mg}$ EDTAE/g sample).

The analysis of the data concerning the sulfurated compounds $\mathbf{1 - 5}$ reveals a strong correlation between the ABTS and FRAP assays. With respect to the comparison between the ferric reducing potential, determined by the FRAP assay, and the metal chelating activity, an interesting behavior can 
be observed for the two thiol molecules, L-cystine (4) and H-Glo(Cys-Gly-OH)-OH (3): They show in fact a $\mathrm{Fe}^{3+}$ reducing power in the low-medium range compared to the more active compounds of 1,2 and 5 . This effect may be due to the strong metal chelating activity of 3 and 4 , not shared by the other compounds in the series, which interfere with the metal ion-containing FRAP assay [32]. It is interesting to note that, with respect to CUPRAC, FRAP values are subjected to larger variations, which can be explained with the iron's slower reaction kinetics if compared to copper, and the reported interferences, occurring particularly with thiols [32].

In our experiments, L-cysteine (1) revealed the strongest free radical scavenging power and metal reducing capacity; it is worth noting that the two Cys-based tripeptides, GSH (2) and its oxa-analogue 3 , although optimally ranked, were less efficient, thus suggesting that the anti-oxidant potential of the sulfydrylated amino acid is negatively affected when it is inserted in $(\alpha)$-glutamyl peptides.

The established potential of the natural anti-oxidant EGT (5) has been confirmed by our results; however, in contrast with previous studies observing the formation of stable bivalent metal complexes through the $\mathrm{SH}$ group, we did not observe a significant metal chelating activity for this thiolate [33]. L-cystine (4) showed a somewhat less relevant activity with respect to 5 . This finding is in agreement with the medium anti-oxidant character of the disulfide unit, which is still able to undergo further oxidation.

As outlined in Table 2, taurine (6) displayed none or very weak activity in DPPH, ABTS, FRAP, and PM assays, manifesting, however, moderate CUPRAC and metal chelating power. The activity of taurine towards free radicals has not been demonstrated incontrovertibly. Although the exact mechanisms underlying the low free radical scavenging effect of this amino acid remain to be established, it has been suggested that it might be due to the lack of a readily oxidizable functional group [34].

Regarding non-sulfurated compounds, both peptides $\mathbf{7}$ and $\mathbf{8}$ are semicarbazone derivatives, and incorporate the non-proteinogenic amino acid, tert-leucine ( $t$ Leu). Ongoing attention is focused on the chemical, conformational, and medicinal aspects of this natural aliphatic residue [35-37]. Due to its $(\alpha)$-branched tert-butyl side chain, $t$ Leu is strongly lipophilic and much more bulky with regards to isomeric leucine and isoleucine. Excellent reports have highlighted the role of this amino acid, in terms of steric and polar effects, in decreasing peptide radical formation and stabilization in vivo [38]. On the other hand, semicarbazones, as well as thiosemicarbazones and hydrazones, are known to possess a wide array of biological activities, essentially due to their ability to form strongly H-bond stabilized chelates with heavy metals [39].

The results of the same panel of tests conducted on Z-tLeu-Asp $(\mathrm{O} t \mathrm{Bu})-\mathrm{Sc}(7)$, Ac- - Leu-LeuAsp $(\mathrm{O} t \mathrm{Bu})-\mathrm{Sc}(8)$, and ethyl 2-(D,L)-tert-butyl-mono-malonate (9) indicated that this set of compounds possess a moderate anti-oxidant character in comparison with the sulfurated ones (Table 2). They were not active in the DPPH assay, and exhibited extremely large variation in their reducing power and metal chelating capacity. We hypothesized that, owing to steric inaccessibility of their $t$ Bu-scaffolds, 7-9 may react very slow or even be inert to DPPH. However, Ac- $t$ Leu-Leu-Asp $(\mathrm{O} t \mathrm{Bu})-\mathrm{Sc}$ (8) showed a complete anti-oxidant profile, with a remarkable activity in ABTS $(48.01 \pm 1.41 \mathrm{mg}$ TE/g sample), CUPRAC ( $81.31 \pm 1.85 \mathrm{mg}$ TE/g sample), FRAP (170.47 $\pm 5.50 \mathrm{mg}$ TE/g sample), $\mathrm{PM}(2.62 \pm 0.13 \mathrm{mmol} \mathrm{TE} / \mathrm{g}$ sample), and metal chelating power $(82.70 \pm 3.01 \mathrm{mg}$ EDTAE $/ \mathrm{g}$ sample) assays. This latter parameter is perfectly in line with the values displayed by the most active chelating agents between the sulfur-containing compounds. Both Z-tLeu-Asp(OtBu)-Sc (7) and 2-(D,L)-tert-butyl-mono-malonate (9) were found devoid of radical scavenging activity; however, $\mathrm{Z}-t \mathrm{Leu}-\mathrm{Asp}(\mathrm{O} t \mathrm{Bu})-\mathrm{Sc}(7)$ is equipotent to Ac- $t$ Leu-Leu-Asp $(\mathrm{O} t \mathrm{Bu})-\mathrm{Sc}(8)$ in regard to $\mathrm{Cu}^{2+}$ reducing power $(84.30 \pm 1.39 \mathrm{mg} \mathrm{TE} / \mathrm{g}$ sample), and its metal chelating activity is still notable, resulting in half the value of the tripeptide ( $43.69 \pm 3.40 \mathrm{mg}$ EDTAE/g sample), although it was less efficient in the FRAP and PM assays. As far as 2-(D,L)-tert-butyl-mono-malonate (9) is concerned, its metal reducing and chelating behavior is modest and very similar to the one exhibited by taurine (6). In conclusion, Z-tLeu-Asp(OtBu)-Sc (7) and Ac- $t$ Leu-Leu-Asp $(\mathrm{O} t \mathrm{Bu})-\mathrm{Sc}(8)$, the first $t$ Leu-containing peptides to 
be tested in vitro for their anti-oxidant potential, disclosed quite interesting properties. The overall behavior of tripeptide 8 is superior compared to dipeptide 7 .

Based on these encouraging data, and for the purpose of obtaining further insights on the protective role of this set of compounds, we investigated 1-9 as inhibitors of acetylcholinesterase (AChE), butyrylcholinesterase (BChE), tyrosinase, $\alpha$-glucosidase, and $\alpha$-amylase. The inhibitory activity results, collected in Table 3, revealed that our compounds are all effective as tyrosinase inhibitors. In particular, L-cysteine (1), H-Glo(Cys-Gly-OH)-OH (3), and L-cystine (4) presented an impressive and quite comparable inhibition profile against the enzyme, with activity values of $216.40 \pm 0.17 \mathrm{mg} \mathrm{KAE} / \mathrm{g}$ sample, $216.95 \pm 0.17 \mathrm{mg} \mathrm{KAE} / \mathrm{g}$ sample, and $217.16 \pm 0.55 \mathrm{mg} \mathrm{KAE} / \mathrm{g}$ sample, respectively. A marked inhibitory effect was evidenced for peptides, Z-tLeu-Asp $(\mathrm{O} t \mathrm{Bu})-\mathrm{Sc}$ (7) and Ac-tLeu-Leu-Asp(OtBu)-Sc (8) (163.87 $\pm 0.90 \mathrm{mg} \mathrm{KAE/g} \mathrm{sample} \mathrm{and} 152.69 \pm 1.19 \mathrm{mg}$ $\mathrm{KAE} / \mathrm{g}$ sample, respectively). The corresponding parameter for EGT (5) resulted ca. half the value of 4 (100.97 $\pm 1.71 \mathrm{mg} \mathrm{KAE/g} \mathrm{sample),} \mathrm{while} \mathrm{GSH} \mathrm{(2),} \mathrm{ethyl} \mathrm{2-(D,L)-tert-butyl-mono-malonate}$ (9), and taurine (6) displayed an almost 5-/6-fold decrease in inhibitory activity with regards to the most active compound $(45.60 \pm 0.15 \mathrm{mg} \mathrm{KAE} / \mathrm{g}$ sample $45.37 \pm 0.52 \mathrm{mg} \mathrm{KAE} / \mathrm{g}$ sample, and $33.87 \pm 1.59 \mathrm{mg} \mathrm{KAE} / \mathrm{g}$ sample, respectively). All compounds were practically inactive towards the other selected enzymes.

\section{Conclusions}

The biological relevance of amino acids and peptides as anti-oxidants and protective agents for human health needs to be explored. They offer the advantages of being non-toxic, potent, and chemically versatile substances, with generally good pharmacokinetics and well-defined metabolic destiny. In this paper, amino acids and peptides were tested in vitro for the first time to assess their anti-oxidant potential and inhibitory activity towards a panel of enzymes involved in the pathogenesis of relevant neurodegenerative and metabolic disorders, including AD and T2D.

Sulfur-containing compounds, 1-5, displayed the best anti-oxidant character in the series. Synthetic peptides, 7 and 8, characterized by the presence of the non-coded $t$ Leu residue in their sequence and derivatized as semicarbazones, showed good metal reducing power and strong metal chelating activity.

Furthermore, an inhibitory effect on tyrosinase activity was observed for all the evaluated compounds. Taken together, our in vitro results demonstrated that the compounds under study could help in reducing the-enzyme-induced toxicity associated with oxidative stress involved in the progression of neurodegenerative and metabolic diseases. Closer investigations will be necessary to unravel the multifaceted potential in the bioactivity of these compounds.

Author Contributions: G.L. synthesized the compounds, wrote the manuscript; A.S. wrote the methods and experimental section, revised the manuscript; G.Z. performed the antioxidant capacity and in vitro biological assay; M.P.D. performed the chemical-physical characterization of the novel compounds; A.M. coordinated the work and collaborated in the rationalization of the data.

Funding: This research received no external funding.

Conflicts of Interest: The authors declare no conflict of interest.

\section{Abbreviations}

$\begin{array}{ll}\text { ABTS } & \text { 2,2'-azino-bis(3-ethylbenzothiazoline-6-sulphonic acid) } \\ \text { ACE } & \text { Acarbose equivalents } \\ \text { AChE } & \text { acetylcholinesterase } \\ \text { AcOEt } & \text { Ethyl acetate } \\ \text { AD } & \text { Alzheimer's disease } \\ \text { ATCI } & \text { Acetylthiocholine iodide } \\ \text { BChE } & \text { Butyrylcholinesterase } \\ \text { BTCI } & \text { Butyrylthiocholine chloride }\end{array}$




$\begin{array}{ll}\text { CECC } & \text { Carnosine Equivalent Iron Chelation Capacity } \\ \text { ChE } & \text { Cholinesterase } \\ { }^{13} \text { C-NMR } & \text { Carbon-13 nuclear magnetic resonance } \\ \text { CUPRAC } & \text { Cupric ion reducing antioxidant capacity } \\ \text { DPPH } & \text { 2,2-diphenyl-1-picrylhydrazyl } \\ \text { DTNB } & \text { 5,5-dithio-bis(2-nitrobenzoic acid) } \\ \text { EDTA } & \text { Ethylenediaminetetraacetic Acid } \\ \text { EECC } & \text { EDTA Equivalent Iron Chelation Capacity } \\ \text { EGT } & \text { L-ergothioneine } \\ \text { EtOH } & \text { Ethanol } \\ \text { FRAP } & \text { Ferric reducing ability of plasma } \\ \text { GALAE } & \text { Galantamine equivalents } \\ \text { GSH } & \text { Gluthatione } \\ \text { HAT } & \text { Hydrogen atom transfer } \\ { }^{1} \text { H-NMR } & \text { Proton nuclear magnetic resonance } \\ \text { KAE } & \text { Kojic acid } \\ \text { L-DOPA } & \text { Levo-dihydroxy-phenylalanine } \\ \text { LPA } & \text { Lipid peroxidation assay } \\ \text { NEAC } & \text { Non enzymatic antioxidant capacity } \\ \text { ORAC } & \text { Oxygen radical absorbance capacity } \\ \text { OS } & \text { Oxidative strees } \\ \text { PM } & \text { Phosphomolybdenum } \\ \text { PNPG } & \text { p-nitrophenol-alfa-D-glucopyranoside } \\ \text { RNS } & \text { Reactive nitrogen species } \\ \text { ROS } & \text { Reactive Oxygen Species } \\ \text { SET } & \text { Single electron transfer } \\ \text { TAC } & \text { Total anti-oxidant capacity } \\ \text { Tau } & \text { Taurine } \\ \text { T2D } & \text { type 2 diabetes } \\ \text { TEAC } & \text { Trolox equivalent antioxidant capacity } \\ \text { TLC } & \text { Thin layer chromatography } \\ \text { TPTZ } & \text { 2,4,6-tris(2-pyridyl)-S-triazine } \\ \text { TRAP } & \text { Total radical trapping antioxidant parameter }\end{array}$

\section{References}

1. Sies, H. Oxidative stress: Oxidants and antioxidants. Exp. Physiol. 1997, 82, 291-295. [CrossRef]

2. Carrasco-Pancorbo, A.; Cerretani, L.; Bendini, A.; Segura-Carretero, A.; Del Carlo, M.; Gallina-Toschi, T.; Lercker, G.; Compagnone, D.; Fernandez-Gutierrez, A. Evaluation of the antioxidant capacity of individual phenolic compounds in virgin olive oil. J. Agric. Food Chem. 2005, 53, 8918-8925. [CrossRef]

3. Rubbo, H.; Batthyany, C.; Radi, R. Nitric Oxide: Oxygen Radical Interactions in Atherosclerosis. Biol. Res. 2000, 33, 167-175. [CrossRef] [PubMed]

4. Wang, X.; Wu, Q.; Liu, A.; Anadón, A.; Rodríguez, J.-L.; Martínez-Larrañaga, M.-R.; Yuan, Z.; Martínez, M.-A. Paracetamol: Overdose-induced oxidative stress toxicity, metabolism, and protective effects of various compounds in vivo and in vitro. Drug Metab. Rev. 2017, 49, 395-437. [CrossRef] [PubMed]

5. Zengin, G.; Abdallah, H.H.; Dogan, A.; Mollica, A.; Aumeeruddy-Elalfi, Z.; Mahomoodally, M.F. Phenolic components and assessment of biological properties of Tchihatchewia isatidea Boiss. extracts: Docking and functional approaches for designing novel products. Food Chem. Toxicol. 2018, 111, 423-431. [CrossRef] [PubMed]

6. Droge, W. Free radicals in the physiological control of cell function. Physiol. Rev. 2002, 82, 47-95. [CrossRef] [PubMed]

7. Sies, H. Oxidative stress: A concept in redox biology and medicine. Redox Biol. 2015, 4, 180-183. [CrossRef] [PubMed] 
8. Radjendirane, V.; Joseph, P.; Jaiswal, A.K. Oxidative Stress and Signal Transduction; Cadenas, E., Forman, H.J., Eds.; Springer: Basel, Switzerland, 1997; pp. 441-469.

9. Bartosz, G. Non-enzymatic antioxidant capacity assays: Limitations of use in biomedicine. Free Radic. Res. 2010, 44, 711-720. [CrossRef] [PubMed]

10. Apak, R.A.; Özyürek, M.; Güçlü, K.; Çapanoğlu, E. Antioxidant activity/capacity measurement. 2. Hydrogen atom transfer (HAT)-based, mixed-mode (electron transfer (ET)/HAT), and lipid peroxidation assays. J. Agric. Food Chem. 2016, 64, 1028-1045. [CrossRef] [PubMed]

11. Metodiewa, D.; Kośka, C. Reactive oxygen species and reactive nitrogen species: Relevance to cyto (neuro) toxic events and neurologic disorders. An overview. Neurotox. Res. 1999, 1, 197-233. [CrossRef]

12. Zhang, P.; Xu, X.; Li, X. Cardiovascular diseases: Oxidative damage and antioxidant protection. Eur. Rev. Med. Pharmacol. Sci. 2014, 18, 3091-3096. [PubMed]

13. Kamat, P.K.; Kalani, A.; Rai, S.; Swarnkar, S.; Tota, S.; Nath, C.; Tyagi, N. Mechanism of Oxidative Stress and Synapse Dysfunction in the Pathogenesis of Alzheimer's Disease: Understanding the Therapeutics Strategies. Mol. Neurobiol. 2016, 53, 648-661. [CrossRef] [PubMed]

14. Tramutola, A.; Lanzillotta, C.; Perluigi, M.; Butterfield, D.A. Oxidative stress, protein modification and Alzheimer disease. Brain Res. Bull. 2017, 133, 88-96. [CrossRef] [PubMed]

15. Furukawa, S.; Fujita, T.; Shimabukuro, M.; Iwaki, M.; Yamada, Y.; Nakajima, Y.; Nakayama, O.; Makishima, M.; Matsuda, M.S.I. Increased oxidative stress in obesity and its impact on metabolic syndrome. J. Clin. Investig. 2004, 114, 1752-1761. [CrossRef] [PubMed]

16. Calcagni, A.; Lucente, G.; Luisi, G.; Pinnen, F.; Rossi, D. Novel glutathione analogues containing the dithiol and disulfide form of the Cys-Cys dyad. Amino Acids 1999, 17, 257-265. [CrossRef] [PubMed]

17. Ferrucci, A.; Leboffe, L.; Agamennone, M.; Di Pizio, A.; Fiocchetti, M.; Marino, M.; Ascenzi, P.; Luisi, G. Ac-tLeu-Asp-H is the minimal and highly effective human caspase-3 inhibitor: Biological and in silico studies. Amino Acids 2015, 47, 153-162. [CrossRef]

18. Mollica, A.; Mirzaie, S.; Costante, R.; Carradori, S.; Macedonio, G.; Stefanucci, A.; Dvoracsko, S.; Novellino, E. Exploring the biological consequences of conformational changes in aspartame models containing constrained analogues of phenylalanine. J. Enzym. Inhib. Med. Chem. 2016, 31, 953-963. [CrossRef]

19. Erdei, A.I.; Borbély, A.; Magyar, A.; Szúcs, E.; Ötvös, F.; Gombos, D.; Al-Khrasani, M.; Stefanucci, A.; Dimmito, M.P.; Luisi, G.; et al. Biochemical and pharmacological investigation of novel nociceptin/OFQ analogues and N/OFQ-RYYRIK hybrid peptides. Peptides 2018, 99, 205-216. [CrossRef]

20. Rauf, A.; Noor, J. Natural Products as a Potential Enzyme Inhibitors from Medicinal Plants, Enzyme Inhibitors and Activators, Murat Senturk. IntechOpen. 2017. Available online: https: / / www.intechopen.com/books/enzyme-inhibitors-and-activators/natural-products-as-a-potentialenzyme-inhibitors-from-medicinal-plants (accessed on 29 March 2017). [CrossRef]

21. Revadigar, V.; Ghalib, R.M.; Murugaiyah, V.; Embaby, M.A.; Jawad, A.; Mehdi, S.H.; Hashim, R.; Sulaiman, O. Enzyme Inhibitors Involved in the Treatment of Alzheimer's Disease. In Drug Design and Discovery in Alzheimer's Disease; Elsevier: Amsterdam, The Netherlands, 2015; pp. 142-198.

22. Kandiah, N.; Pai, M.-C.; Senanarong, V.; Looi, I.; Ampil, E.; Park, K.W.; Karanam, A.K.; Christopher, S. Rivastigmine: The advantages of dual inhibition of acetylcholinesterase and butyrylcholinesterase and its role in subcortical vascular dementia and Parkinson's disease dementia. Clin. Interv. Aging 2017, 12, 697-707. [CrossRef]

23. Lee, S.Y.; Baek, N.; Nam, T.-G. Natural, semisynthetic and synthetic tyrosinase inhibitors. J. Enzym. Inhib. Med. Chem. 2016, 31, 1-13. [CrossRef]

24. Tief, K.; Schmidt, A.; Beermann, F. New evidence for presence of tyrosinase in substantia nigra, forebrain and midbrain. Mol. Brain Res. 1998, 53, 307-310. [CrossRef]

25. Xu, L.; Li, Y.; Dai, Y.; Peng, J. Natural products for the treatment of type 2 diabetes mellitus: Pharmacology and mechanisms. Pharmacol. Res. 2018, 130, 451-465. [CrossRef] [PubMed]

26. Mollica, A.; Zengin, G.; Durdagi, S.; Ekhteiari, S.R.; Macedonio, G.; Stefanucci, A.; Dimmito, M.P.; Novellino, E. Combinatorial peptide library screening for discovery of diverse $\alpha$-glucosidase inhibitors using molecular dynamics simulations and binary QSAR models. J. Biomol. Struct. Dyn. 2018, 22, 1-15. [CrossRef] [PubMed] 
27. Luisi, G.; Mollica, A.; Carradori, S.; Lenoci, A.; De Luca, A.; Caccuri, A.M. Nitrobenzoxadiazole-based GSTP1-1 inhibitors containing the full peptidyl moiety of (pseudo) glutathione. J. Enzym. Inhib. Med. Chem. 2016, 31, 924-930. [CrossRef] [PubMed]

28. Colantonio, P.; Leboffe, L.; Bolli, A.; Marino, M.; Ascenzi, P.; Luisi, G. Human caspase-3 inhibition by Z-tLeu-Asp-H: TLeu (P2) counterbalances Asp (P4) and Glu (P3) specific inhibitor truncation. Biochem. Biophys. Res. Commun. 2008, 377, 757-762. [CrossRef] [PubMed]

29. Grochowski, D.M.; Uysal, S.; Aktumsek, A.; Granica, S.; Zengin, G.; Ceylan, R.; Locatelli, M.; Tomczyk, M. In vitro enzyme inhibitory properties, antioxidant activities, and phytochemical profile of Potentilla thuringiaca. Phytochem. Lett. 2017, 20, 365-372. [CrossRef]

30. Calcagni, A.; Duprè, S.; Lucente, G.; Luisi, G.; Pinnen, F.; Rossi, D.; Spirito, A. Synthesis and Activity of the Glutathione Analogue $\gamma$-(L- $\gamma$-Oxaglutamyl)-L-cysteinyl-glycine. Arch. Pharm. 1996, 329, 498-502. [CrossRef]

31. Cheah, I.K.; Halliwell, B. Ergothioneine; antioxidant potential, physiological function and role in disease. Biochim. Biophys. Acta 2012, 1822, 784-793. [CrossRef] [PubMed]

32. Apak, R.A.; Özyürek, M.; Güçlü, K.; Çapanoğlu, E. Antioxidant activity/capacity measurement. 1. Classification, physicochemical principles, mechanisms, and electron transfer (ET)-based assays. J. Agric. Food Chem. 2016, 4, 997-1027. [CrossRef]

33. Motohashi, N.; Mori, I.; Sugiura, Y.; Tanaka, H. Metal complexes of ergothioneine. Chem. Pharm. Bull. 1974, 22, 654-657. [CrossRef]

34. Patel, S.N.; Pandya, K.; Clark, G.J.; Parikh, M.C.; Lau-Cam, C.A. Comparison of taurine and pantoyltaurine as antioxidants in vitro and in the central nervous system of diabetic rats. Exp. Toxicol. Pathol. 2016, 68, 103-112. [CrossRef] [PubMed]

35. Bold, G.; Fässler, A.; Capraro, H.-G.; Cozens, R.; Klimkait, T.; Lazdins, J.; Mestan, J.; Poncioni, B.; Rösel, J.; Stover, D. New aza-dipeptide analogues as potent and orally absorbed HIV-1 protease inhibitors: Candidates for clinical development. J. Med. Chem. 1998, 41, 3387-3401. [CrossRef] [PubMed]

36. Bommarius, A.S.; Schwarm, M.; Stingl, K.; Kottenhahn, M.; Huthmacher, K.; Drauz, K. Synthesis and use of enantiomerically pure tert-leucine. Tetrahedron Asymmetry 1995, 6, 2851-2888. [CrossRef]

37. Lyu, P.C.; Sherman, J.C.; Chen, A.; Kallenbach, N.R. Alpha-helix stabilization by natural and unnatural amino acids with alkyl side chains. Proc. Natl. Acad. Sci. USA 1991, 88, 5317-5320. [CrossRef] [PubMed]

38. Croft, A.K.; Easton, C.J.; Radom, L. Design of radical-resistant amino acid residues: A combined theoretical and experimental investigation. J. Am. Chem. Soc. 2003, 125, 4119-4124. [CrossRef]

39. Palanimuthu, D.; Wu, Z.; Jansson, P.J.; Braidy, N.; Bernhardt, P.V.; Richardson, D.R.; Kalinowski, D.S. Novel chelators based on adamantane-derived semicarbazones and hydrazones that target multiple hallmarks of Alzheimer's disease. Dalton Trans. 2018, 47, 7190-7205. [CrossRef] [PubMed] 